\title{
Sistem Informasi Agenda Surat Studi Kasus - Disporabud Pamekasan
}

\author{
Eka Mala Sari Rochman \\ Teknik Multimedia dan Jaringan, Fakutas Teknik, Universitas Trunojoyo \\ ekamalasari3@gmail.com
}

\begin{abstract}
ABSTRAK
Kemampuan menggunakan teknologi informasi dibutuhkan oleh masyarakat indonesia untuk menerima serta menerapkannya dalam berbagai aspek kehidupan untuk memudahkan penggunanya. Dalam perusahaan atau industry membutuhkan sebuah sistem yang dapat mempermudah untuk pengaturan aliran data masuk maupun data keluar. Utamanya dalam hal surat menyurat. Karena dalam hal ini, pengelolaan masih dilakukan secara manual dan tidak tertib maka dibutuhkan sebuah sistem informasi tentang agenda surat. Dalam sistem informasi agenda surat ini dapat menyimpan, memperbaharui surat masuk maupun keluar serta membuat laporan tentang semua arsip semua surat yang ada dalam instansi. Dengan adanya sistem ini, maka semua proses surat menyurat dalam sebuah lembaga menjadi lebih tertib dan tidak adanya keterlambatan penerimaan informasi.
\end{abstract}

Kata Kunci: Sistem Informasi, Surat masuk, Surat keluar, laporan

$$
\begin{aligned}
& \text { Information Systems Corespondence } \\
& \text { Case Study - Disporabud Pamekasan }
\end{aligned}
$$

\section{ABSTRACT}

The ability of information technology required by Indonesian society to accept and implement them in various aspects of life to facilitate users. In the company or industry requires a system that can make it easier to control the data flow of incoming and outgoing data. Primarily in terms of correspondence. Because in this case, the management is still done manually and undisciplined then needed an information system on the agenda of the letter. In this letter the agenda information system can store, update, incoming and outgoing mail and to report on all archive all mail in the institution. With this system, then all the correspondence in an institution becomes more orderly and no delay in receipt of information.

Keywords: information systems, incoming mail, outgoing mail, report. 


\section{PENDAHULUAN}

Teknologi informasi yang maju pesat telah diadopsi oleh indonesia. Kemampuan menggunakan teknologi informasi dibutuhkan oleh masyarakat indonesia untuk menerima serta menerapkan teknologi informasi dalam berbagai aspek kehidupan untuk memudahkan penggunanya. Teknologi informasi hendaknya dipusatkan pada pemanfaatan, pengembangan, dan penguasaan untuk mempercepat proses perbaikan, peningkatkan produktifitas dan efisiensi, perluasan lapangan kerja, peningkatan kualitas, harkat dan martabat serta kesejahteraan masyarakat [1].

Berbagai perusahaan, industri, dan instansi sekarang sudah menggunakan sebuah sistem yaitu sistem informasi, baik dalam kegiatan akademik maupun dalam kegiatan perkantoran untuk mempermudah proses aktifitasnya sehari-hari. Biasanya untuk perusahaan, industri, dan instansi yang telah maju saja yang sudah menggunakan sistem informasi, sedangkan yang masih berkembang masih belum mengetahuinya dan masih pasif untuk mengadopsinya.

Berdasarkan uraian dalam latar belakang masalah tersebut, maka dilakukan penelitian masalah yang akan dituangkan dalam bentuk pembembuatan sebuah sistem informasi yang berbasis web.

Batasan dari penelitian ini adalah pada cara menyajikan informasi yang diimplementasikan pada Sistem Informasi Agenda Surat Berbasis Web dari arsip surat manual yang dimilikinya. Sistem Informasi Agenda Surat ini hanya berfungsi sebagai alat pencatatan (Entry Data), pencarian (Searching), dan pencetakan (Print) laporan sesuai dengan keperluan data surat di DISPORABUD (Dinas Pemuda Olahraga dan Kebudayaan) Kabupaten Pamekasan.

\section{METODE PENELITIAN}

Sistem adalah kumpulan dari beberapa elemen yang saling berintegrasi untuk mencapai tujuan tertentu. Elemen-elemen yang mewakili suatu sistem secara umum adalah masukan (input), pengolahan (processing) dan keluaran (output) [2]. Elemen-elemen sistem secara garis besar adalah input, proses dan output. Sistem mempunyai karakteristik atau sifat - sifat tertentu, yaitu :

1. Komponen Sistem

2. Batasan Sistem

3. Lingkungan Luar Sistem

4. Masukan Sistem

5. Keluaran Sistem

6. Pengolahan Sistem

7. Sasaran Sistem

Informasi adalah data yang diolah menjadi bentuk yang berguna dan menjadi berarti bagi penerimanya. Kegunaan informasi adalah untuk mengurangi ketidakpastian di dalam proses pengambilan keputusan tentang suatu keadaan. Suatu informasi dikatakan bernilai bila manfaatnya lebih efektif dibandingkan dengan biaya untuk mendapatkan informasi tersebut. Kualitas informasi sangat dipengaruhi atau ditentukan oleh beberapa hal yaitu:

1. Relevan (Relevancy)

2. Akurat (Accurancy)

3. Tepat waktu (Time liness)

4. Ekonomis (Economy)

5. Efisien (Efficiency)

6. Ketersediaan (Availability)

7. Dapat dipercaya (Reliability)

8. Konsisten 
Data merupakan deskripsi dari sesuatu dan kejadian yang kita hadapi. Data adalah fakta yang jelas lingkup, tempat, dan waktunya. Data diperoleh dari sumber data primer atau sekunder dalam bentuk berita tertulis atau sinyal elektronis. Jadi pada intinya, data merupakan kenyataan yang menggambarkan suatu kejadian dan merupakan kesatuan nyata yang nantinya akan digunakan sebagai bahan dasar suatu informasi.

Sistem Informasi $\begin{array}{r}\text { Berbasis } \\ \text { Komputer merupakan sistem }\end{array}$
pengolah data menjadi sebuah
informasi yang berkualitas dan
dipergunakan untuk suatu alat bantu
pengambilan keputusan. Sistem
Informasi yang akurat dan efektif,
dalam kenyataannya selalu
berhubungan dengan istilah
"computer-based" atau pengolahan
informasi yang berbasis pada
komputer. Sistem Informasi
"berbasis komputer" mengandung
arti bahwa komputer memainkan
peranan penting dalam sebuah
sistem informasi. [3]

Secara teori, penerapan sebuah Sistem Informasi memang tidak harus menggunakan komputer dalam kegiatannya. Tetapi pada prakteknya tidak mungkin sistem informasi yang sangat kompleks itu dapat berjalan dengan baik jika tanpa adanya komputer. Sistem Informasi merupakan sistem pembangkit informasi. Dengan integrasi yang dimiliki antar subsistemnya, sistem informasi akan mampu menyediakan informasi yang berkualitas, tepat, cepat dan akurat sesuai dengan manajemen yang membutuhkannya [4].

\section{Kemampuan Sistem Informasi}

Sistem informasi tentunya memiliki kemampuan sebagai berikut:
1. Memiliki kecepatan akses tinggi, high-volume, komputasi numerik.

2. Menyediakan kecepatan, komunikasi yang akurat.

3. Menyimpan informasi dalam jumlah besar dan mudah untuk digunakan.

4. Akses yang cepat dan tidak mahal untuk mendapatkan informasi, dan mendunia.

5. Fasilitas untuk menginterpretasikan sejumlah data yang besar.

6. Meningkatkan efektifitas dan efisiensi dari orang-orang yang bekerja dalam kelompok dalam satu tempat atau dalam lokasi yang berbeda, dimana saja.

7. Mengotomatisasi proses bisnis dan pekerjaan manual.

\section{Procedure Kebutuhan Sistem}

Procedure yang dibutuhkan oleh sistem informasi ini meliputi:

1. Penambahan Data. Stored procedure ini digunakan untuk menambahkan data pada tabel tertentu.

2. Penghapusan Data. Stored procedure ini berfungsi untuk menghapus data yang telah ada pada server basis data.

3. Penampilan Data. Stored procedure ini digunakan untuk menampilkan data pada tabel tertentu sesuai kondisi yang diinginkan.

4. Pengubahan Data. Stored procedure ini digunakan untuk mengubah data yang telah ada pada server basis data. 


\section{Kebutuhan Masukan Sistem}

Adapun masukan data untuk sistem adalah sebagai berikut :

1. Data agenda surat.

Data agenda surat disini meliputi data-data arsip surat yang dimiliki oleh DISPORABUD Kabupaten Pamekasan

2. Data admin.

Data admin merupakan data login user yang bertindak sebagai admin untuk mengelola data-data yang ada pada sistem.

\section{HASIL DAN PEMBAHASAN}

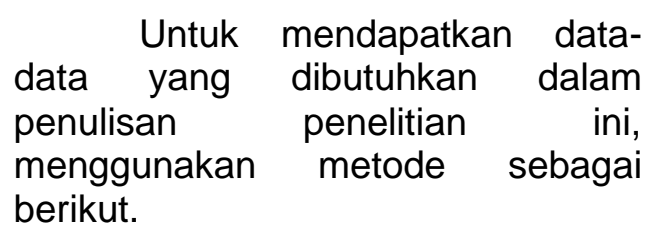

\section{Sumber Data Primer}

Data primer ini merupakan data dari hasil wawancara, Pengamatan lansung kelapangan (Observasi), dan permintaan keterangan terhadap pihak DISPORABUD Kabupaten Pamekasan mengenai semua sistem yang sedang berjalan.

\section{Sumber Data Sekunder}

Data sekunder ini merupakan data dokumentasi DISPORABUD, yang dilakukan dengan pengumpulan data tertulis yaitu kegiatan memperoleh data-data dengan menganalisis da mempelajari dokumen-dokumen atau catatan yang ada di DISPORABUD. Dengan melakukan penelitian dimana dalam pengambilan datanya penulis melakukan pengambilan contoh data surat keluar dan surat masuk yang digunakan untuk pelengkap data yang diperoleh.

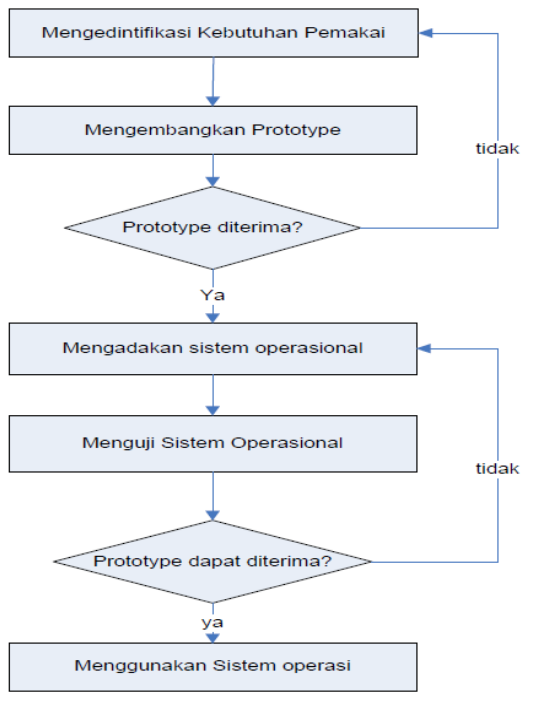

Gambar 1. Metode Prototype

\section{Metode Pembangunan Sistem}

Langkah umum penggambaran prototyping adalah sebagai berikut :

1. Mengidentifikasikan kebutuhan pemakai. Pada tahap ini analis sistem akan melakukan studi kelayakan dan studi terhadap kebutuhan pemakai. Baik yang meliputi model interface, teknik procedural maupun dalam teknologi yang akan digunakan.

2. Mengembangkan prototype untuk memperlihatkan pemodelan sistem yang akan digunakan.

3. Menentukan apakah prototype dapat diterima oleh pemakai sistem yaitu pihak DISPORABUD Kabupaten pamekasan.

4. Mengadakan sistem operasional melalui pemograman sistem oleh pemograman berdasarkan pemodelan sistem yang telah disepakati.

5. Menguji sistem operasional. Pada tahap ini dilakukan uji coba terhadap sistem yang dibuat untuk memastikan bahwa sistem dapat berlangsung dengan baik dan benar. 
6. Menentukan sistem operasional mengenai sistem informasi yang telah dibuat.

7. Jika sistem telah disetujui, maka tahap terakhir adalah melakukan implementasi sistem.

\section{Use Case}

Use case merepresentasikan sebuah interaksi antara user dengan sistem dan menggambarkan fungsionalitas yang diharapkan dari sebuah sistem.

\section{Halaman Web}

Halaman web merupakan interface antara user/petugas yang terlibat langsung dengan sistem yang ada dan dikarenakan berbasis web, sehingga mempermudah user dalam menggunakan sistem. Adapun interface yang ada adalah sebagai berikut :

\section{Halaman Login}

Halaman ini berfungsi sebagai keamanan, dimana setiap kali akan melakukan pengeditan, pengentrian, dan penghapusan data harus melewati halaman ini dengan

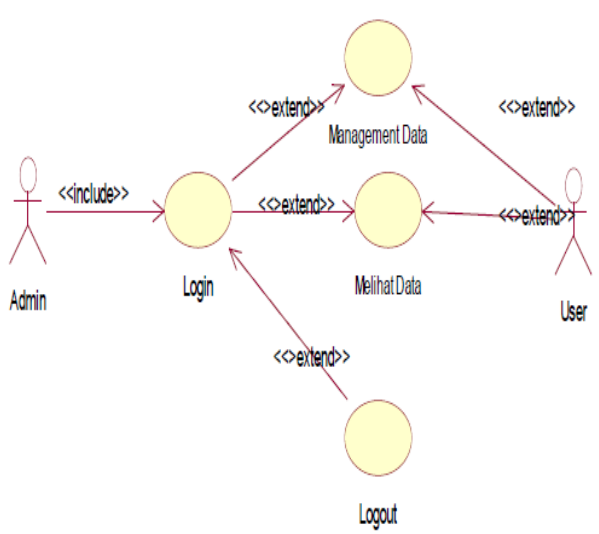

Gambar 2. Use case memasukkan data user dan password admin.

\section{Halaman Utama}

Halaman ini merupakan halaman kumpulan sistem informasi pada website ini. Gambar 4 menunjukkan tampilan halaman utama

\section{Halaman Surat Masuk}

Di dalam halaman surat masuk ini admin dapat menginput, mengupdate, mendelete dan mencetak data surat yang ada sebagai arsip. Sekaligus dapat searching atau mencari surat yang ada baik berdasarkan no, perihal maupun tahun, bahkan dalam aplikasi ini user dapat memberikan report dari arsip surat yang ada berdasarkan tanggal, bulan dan tahun yang diinginkan. Gambar 4 menunjukkan halaman surat masuk.

\section{Halaman Masukkan Data}

Halaman ini admin dapat memasukkan data dengan memasukkan no urut, alamat pengirim, tanggal masuk, no surat, dan perihal.

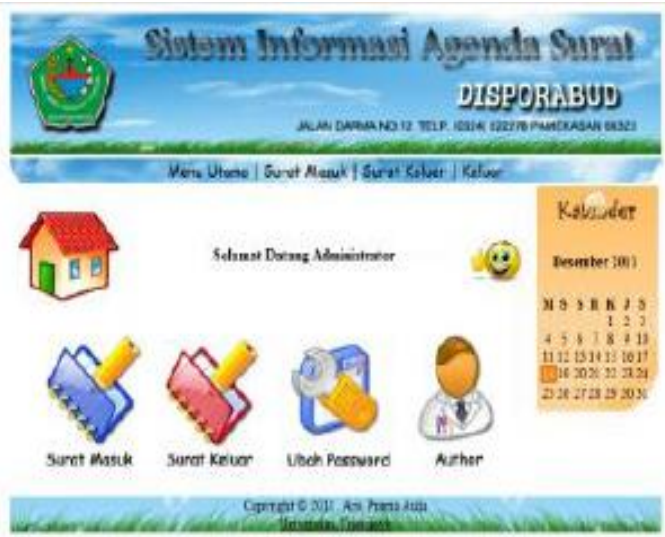

Gambar 3. Halaman utama 


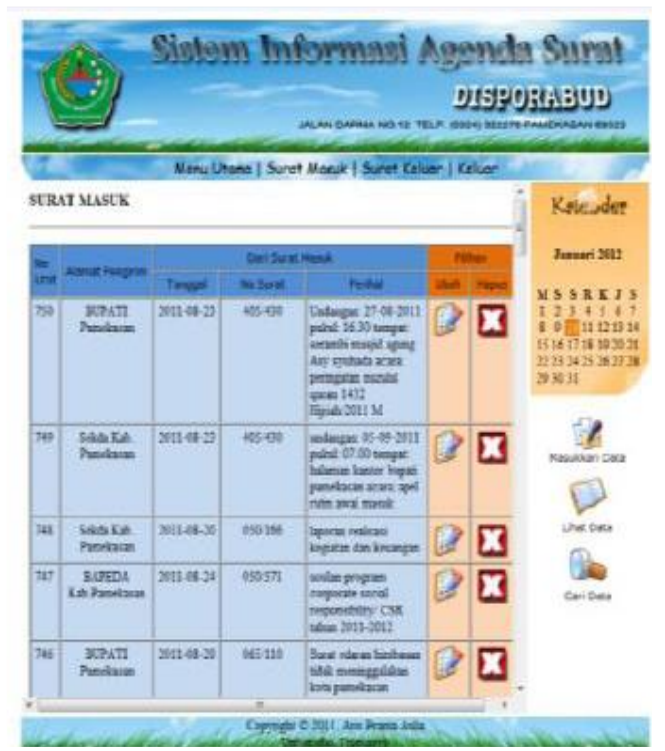

Gambar 4. Halaman Surat Masuk

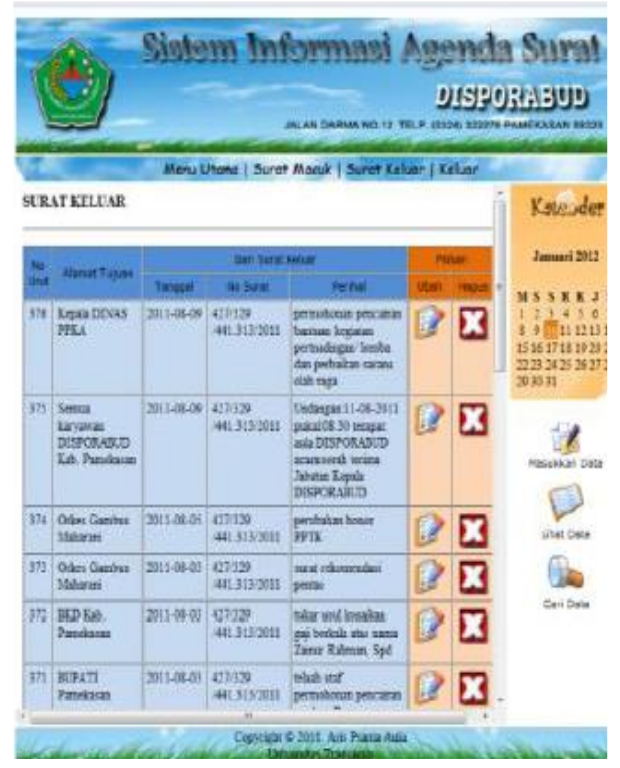

\section{Gambar 6. Halaman Surat Keluar}

5. Halaman Ubah data

Halaman ini akan tampil setelah anda meng-klik data yang akan diubah. Dapat mengubah no urut, alamat pengirim, tanggal, no surat dan perihal.

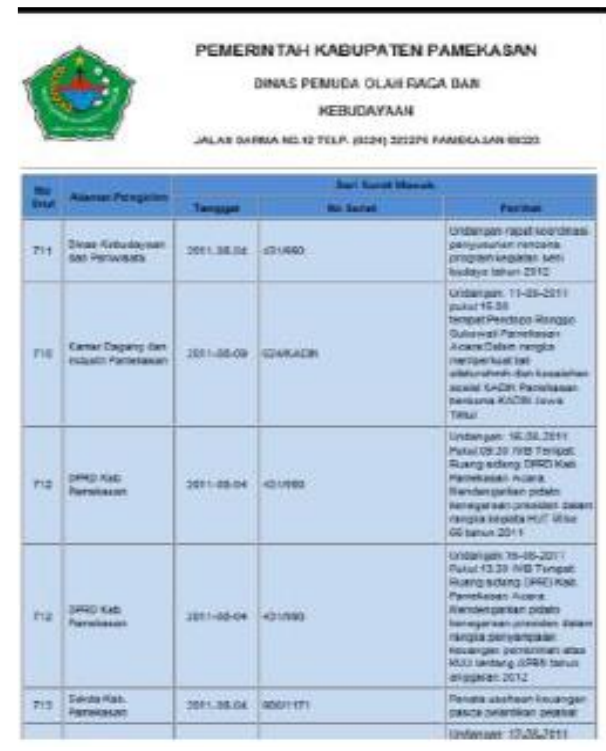

Gambar 5. Halaman Report

\section{Halaman Cari Data}

Halaman ini berfungsi untuk pencarian data surat masuk. Pencariannya bisa berdasarkan no, perihal dan tanggal surat masuk.

\section{Halaman Cetak Data}

Pada halaman ini admin dapat mencetak arsip surat masuk.

8. Halaman Report

Pada halaman ini admin dapat membuat report dari hasil surat-surat yang ada pada surat masuk berdasarkan tanggal. Gambar 5 menunjukkan halaman report.

\section{Halaman Surat Keluar}

Sama halnya dengan surat masuk, di dalam halaman input data surat keluar ini admin dapat menginput, mengupdate, mendelete dan mencetak data surat yang ada sebagai arsip. Sekaligus dapat searching atau mencari surat yang ada baik berdasarkan no, perihal maupun tahun, bahkan dalam aplikasi ini user dapat memberikan report dari arsip surat yang ada 
berdasarkan tahun. Gambar 6 menunjukkan halaman surat keluar.

\section{SIMPULAN}

diperoleh beberapa simpulan sebagai berikut:

1. Sistem informasi yang dibuat telah sesuai dengan langkahlangkah pembuatan sistem informasi untuk agenda surat.

2. Laporan pada sistem informasi agenda surat sesuai dengan dasar sistem sebelumnya.

\section{DAFTAR PUSTAKA}

Wartawarga, "Perkembangan Teknologi Informasi".

Ilham, "Pengertian Sistem Informasi”, Universitas Sumatera Utara, Sumatera Utara, 2010.

Sutarman, S.Kom "Membangun Aplikasi Web dengan PHP dan
3. Sistem informasi yang dibuat memiliki menu-menu input data surat masuk, surat keluar, edit data, searching, menghapus data dan cetak data. Dari pembuatan sistem bantu ini karyawan khususnya bagian administrasi agenda surat tidak perlu melakukan agenda surat secara manual. Dan untuk mempermudah dan mempercepat proses kerja pembuatan rekapitulasi agenda surat di DISPORABUD Kabupaten Pamekasan.

MySQL", Graha IImu, Yogyakarta, 2003

Kustiyahningsih, Yeni, dan Devi Rosa Anamisa, "Pemrograman Basis Data Berbasis Web Menggunakan PHP \& Mysql", Graha IImu, Yogyakarta, 2011. 